\title{
Individual Stakeholder's Surveillance System on Financing Risks in large-scale construction projects
}

\author{
Zhao Hui ${ }^{12}$ \\ School of Management, Qingdao Technological University, Shandong, 266520,China \\ E-mail: Zhaohui430126.com \\ Huang Wei-Jie ${ }^{3}$ \\ School of Management, Qingdao Technological UniversityShandong, 266520,China \\ E-mail: Huangwjjiangyin@hotmail.com
}

\section{Sheng-Ping Wang}

School of Management, Qingdao Technological UniversityShandong, 266520,China

E-mail: 694520216@qq.com

To make the stakeholders of large-scale construction project control their financing risks accurately and timely, the paper proposes the idea that financing risks should be shared between individual stakeholders firstly and then evaluated so that each one will better know and control his/her shared risks. Based on this idea and the help of modern information technologies, the paper built a surveillance system for large-scale construction project's financing risks from the perspective of individual stakeholder. Finally, an example, Qingdao Jiaozhou Bay Subsea Tunnel Project, is used to illustrate the surveillance process. The surveillance system provides a valuable tool for the individual stakeholder to control financing risks.

CENet 2015

12-13 September 2015

Shanghai, China

\footnotetext{
${ }^{1}$ Speaker

${ }^{2}$ Corresponding Author

${ }^{3}$ This paper is one of the achievements of National Natural Science Fund Project of China (No.71471094), Shandong Provincial National Natural Science Fund Project of China (No.ZR2011GL021) and Shandong Provincial Education Department Fund Project (No.J10WG60). Thus the authors would like to appreciate National Natural Science Foundation of China, Shandong Provincial National Natural Science Foundation of China and Shandong Provincial Education Department for their fund.
} 


\section{Introduction}

Today, the scale and requirements of the construction projects have changed fundamentally. Influenced by social needs, diversified investment, progress in construction technologies and improved project management theories, projects are becoming larger and more complex.

Nowadays, almost all large-scale construction projects have applied project financing to solve the capital shortage, however, it is worth noting that adopting project financing as a means of raising funds is a double-edged sword. It does solve the problem of capital shortage; however, as the demand of capital is getting bigger with longer duration and more complicated structure, the overall risk of large-scale construction project is getting extremely huge, inevitably leading to the stakeholders bearing high risks. Financing risks has become the core problem of the financing for large-scale construction projects, which will directly affect the success of the financing process and its completion.

Scholars have paid much efforts to the control of the financing risks in construction projects. By sorting out the current research achievements, some deficiencies are found as follows.

- Most scholars regard stakeholders as a whole [1] while few scholars separate the stakeholders. For example, in PPP (Public Private Partnership) projects, the stake-holders are just divided into two parties [2,3], public and private sectors. There is no further detailed classification, which will result in different individual stakeholders having much difficulty in the management of their own financing risks.

-When evaluating financing risks, the popular practice [4-5] is to take all the risks that a construction project might encounter as a whole, regardless of taking different phases [6] into consideration. Few scholars considered different phases; however, they just simply divide the whole process into constructing and running phase [7], which has thus caused the insufficiency in promptness and pertinence to the financing risk evaluation.

-In practice, the methods adopted to establish the index and evaluate the project financing risks are still staged in traditional means $[8,9]$ while some mature methods in other fields [10] are rarely applied.

These existing problems convey that the surveillance system of large-scale construction project's financing risks pertinent to the individual stakeholder is far from perfection. Given that, this paper tries to build a specific surveillance system for financing risks form the individual stakeholder's perspective. Firstly, the target risk processed by Data Warehouse (DW), Data Mining (DM) and On-line Analytical Processing (OLAP) is shared through the sharing model. Then, through the evaluation model we will get the actual and threshold risk value of each individual stakeholder. By comparing the two values, the individual stakeholder will know which risk observes extra attention. Hence, this surveillance system is more assistant in controlling financing risks timely and accurately.

\section{Overall Design Of The Large-Scale Construction Project'S Financing Risk Surveillance System}

\subsection{Overall Concept}

From the perspective of equilibrium theory [11], when the external force acting on an object is greater than its tolerance, the deformation occurs. Based on this, the individual stakeholder can measure the status of the financing risk by comparing the actual financing risk value at a certain point with the maximum bearable financing risk value. By means of comparison, the individual stakeholder can operate the surveillance over the financing risk.

Besides, to solve the existing problems above, the surveillance system designed for the individual stakeholder must adhere to the following two principles. 
Easy to understand. With regard to the individual stakeholder, he/she may not have the professional knowledge, in this sense, the straighter the outcome is, the better will be as to the individual stakeholder. Based on this, the design of the surveillance system should pay attention to the easiness of conducting and understanding.

Dynamic. The surveillance system of individual stakeholder must correlate to the schedule of the large-scale construction project, which means the surveillance on financing risk [12] must keep pace with time.

\subsection{Logical Structure}

Based on the design ideas and principles and to make the individual stakeholder better to realize the surveillance over his financing risks [13], the logical structure of the surveillance system is showed in Fig.1.

Its logical process can be described as follows.

The optimized target data are achieved by processing the raw data of a large-scale construction project's financing risks at a certain time point by means of modern information technologies (Data Warehouse, Data Mining and Online Analytical Processing).

Every individual stakeholder gets their own financing risks by sharing the total optimized financing risks at a certain time, which can be realized by using the financing risk sharing model to conduct the optimized target datum.

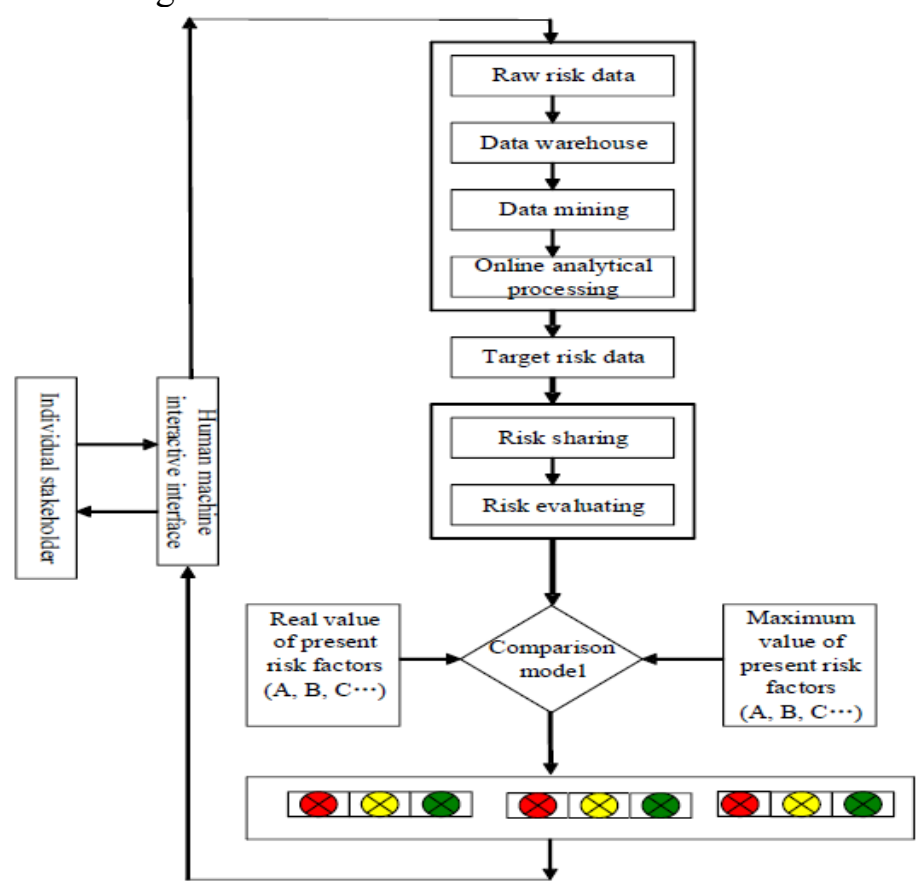

Figure 1 : Logical Structure of the Surveillance System of Financing Risks in the Large-scale Construction Project from the Perspective of Individual Stakeholder

Evaluate every financing risk indicator of an individual stakeholder at a certain time, and then compare the evaluating value with the maximum bearable financing risk value. The compared outcome can be displayed by warning lights colored in red, yellow and green. The red light indicates that the present actual value of a certain risk indicator has surpassed the bearable maximum value. The yellow light shows that the present actual value of a certain risk indicator is close to the bearable maximum value. The green light means the present actual value of a certain risk indicator is within safety scope.

Based on the brief description to the structure, it is not hard to find that there is advantage that the individual stakeholder can not only grasp his own risk situation timely, but also can find 
out the financing risk situation raised by which factor. All these would lay a sound foundation for further management.

\subsection{Realization Techniques}

Data Warehouse (DW).

DW is used in the cleaning, extracting and converting of the data stored in traditional database and it can reorganize the information according to the decision-maker's needs. The physical structure of the data warehouse is usually represented in the form of the star-shaped structure. This kind of highly centralized data provides a valuable analysis basis for various decision-making demands [14].

\section{Data Mining (DM).}

DM is a process of extracting the implicit useful information and knowledge that people usually don't know in advance but potentially useful from vast, incomplete, noisy, hazy and random data generated in application. Data mining is a process of decision support, which is mainly based on technologies like Artificial Intelligence, Machine Learning, Pattern Recognition, Statistics, Database and Visualization Technology to analyze the datum in a highly atomized way.

\section{On-line Analytical Processing (OLAP).}

OLAP focuses on data analysis and converts the analyzed data into auxiliary decisionmaking information. The typical application of OLAP is the slice and dice, drill and rotation etc. of multidimensional data, which is beneficial to the users to extract the relevant data from different angles. OLAP is also capable of analyzing and processing the data in depth through the analyzing progress.

\section{Financing Risk Sharing and Evaluating Model}

To make the individual stakeholder better realize his surveillance over his financing risks in large-scale construction project financing, it is vital to accurately achieve his own financing risks [15] and evaluate it scientifically and reasonably.

\subsection{Sharing Model}

As to risk sharing problem, some scholars like Timothy Irwin [16], Shouqing Wang [17], Shuibo Zhang and Bosen He [18], etc. have studied this problem. Based on current researches, a highly recognized risk sharing principle can be summarized as the risks that should be distributed to the ones who are the most suitable to take. Based on this principle, this paper proposes a financing risk sharing model in large-scale construction project in combination with grey relational grade analysis and entropy method. Grey relational grade reflects the order of the evaluated objects. The bigger grey relational grade is, the better the corresponding evaluated object will be. How to define the index weights has a huge influence on the scientific of grey relational grade? Entropy method can reflect the utility value of information entropy. The index weights given by entropy method have higher credibility; as a result, the paper uses entropy method to determine the index weights. By using the financing risk sharing model, the individual stakeholder will achieve his bearing financing risk factors.

The detailed logical steps of this financing risk sharing model are as follows.

Determining analytical array.

Determine the reference data array which reflects characteristics of system behaviors and the correlation data array that affects the system behavior. The data array that reflects the characteristics of system behaviors is named as reference data array, while what affects the system behavior is named as correlation data array.

Define the reference data array as $Y=\{Y(k) / k=1,2, \ldots, n\}$. Define the correlation data array as $X_{i}=\left\{X_{i}(k)\right\}, k=1,2, \ldots, n, i=1,2, \ldots, n$.

Non-dimensionalizing variables. 
Due to different dimensions of the factors in the system, these factors are incomparable or it is impossible to get the right conclusion. As a result, when undertaking the grey relational grade analysis, the data dimensions have to be removed.

$$
x_{i}(k)=\frac{X_{i}(k)}{X_{i}(l)}, k=1,2, \ldots, n ; i=1,2, \quad, m .
$$

Determining the weight of every index by entropy method.

Define $w_{i}$ as the weight of index, $W=\left\{w_{i}\right\}$, In order to get more reasonable weight, the highly recognized entropy method is used here. The detailed steps are shown as follows.

Firstly, construct a judgment matrix $\mathrm{O}$, composed by $m$ samples and $n$ evaluation indicators. $O=\left(x_{i j}\right)_{m n}, i=1,2, \ldots, n ; j=1,2, \ldots, n$;

Considering that the dimension of each indicator is different, to make it easy to compare, the initial matrix needs to be non-dimensionalized and the process is also called normalization processing. For positive indicators, $e_{i j}=x_{j}-x_{\min } / x_{\max }-x_{\min }$; for negative indicators, $e_{i j}=x_{\max }-x_{j} / x_{\max }-x_{\min }$. Among the equation, $x_{j}$ is the $j$ th indicator, $j=1,2, \ldots, n ; x_{\max }$ is the maximum of $j$ th indicator, $x_{\min }$ is the minimum of $j$ th indicator, $\varepsilon_{i}$ is the standardized value. Based on the above process, the standardized matrix is $E=\left(e_{i j}\right)_{m \times n}$.

According to the definition of entropy, the information entropy $P_{i j}$ of the $j$ th indicator is $P_{i j}=e_{i j} / \sum_{i=1}^{m} e_{i j}$.

Calculate the entropy $s_{j}$ of the $j t h$ indicator $s_{j}=-k \sum_{i=1}^{m} P_{i j} \ln \left(P_{i j}\right)$. Among the equation, $k=1 / \ln (m)$. When the number $m$ of the evaluation samples is determined, $k$ is a constant.

Calculate the entropy weight of all financing risk evaluation indicators.

Entropy weight, calculated by using the value coefficient of each indicator's information, is the weight of the information amount each indicator signaled to the decision maker among the total information. The higher the coefficient value is, the greater the affection will get. The entropy weight of each indicator is:

$$
w_{j}=\left(1-s_{j}\right) / \sum_{j=1}^{n}\left(1-s_{j}\right)
$$

Calculate the correlation coefficient.

Define the correlation coefficient $x_{0}(k)$ and $x_{i}(k)$ as $\delta_{i}$.

$$
\delta_{i}(k)=\frac{\operatorname{minmin}_{i}\left(y(k)-x_{i}(k)\right)+\underset{i}{\operatorname{minmin}}\left(y(k)-x_{i}(k)\right)}{\left(y(k)-x_{i}(k)\right)+\rho_{i}^{\operatorname{maxmax}}\left(y(k)-x_{i}(k)\right)} .
$$

$\rho \in(0, \infty)$, which is termed as identification coefficient. When $\rho$ gets smaller, the power of identification is greater. Generally, the value of $\rho$ is in the interval of $(0,1)$, the specific value depends on the specific situation. When $\rho \leqslant 0.546$, the power of identification is optimal. Usually, $\rho=0.5$.

Calculate the relational grade.

The number of the correlation coefficient is more than just one as it is the value of the relational grade at every time point between the reference data array and the correlation data array. When the data distribution is too scattered, it is inconvenient to compare these data; in this sense, it is necessary that the correlation coefficient of every time point should be processed into one, which is the average value of different correlation coefficients. It is served as a tool to measure the relational grade between the reference data array and the correlation data array. Define $r_{i}$ as the relational grade.

$$
r_{i}=\frac{1}{n} \sum_{k=1}^{n} \varepsilon_{i}(k), k=1,2, \ldots, n
$$

Sort the relational grade.

The relational grades are sorted by size. If $r_{1}<r_{2}$, the reference data array $y$ is more similar to the correlational data array $x_{2}$. 
After the correlational coefficients of sequence $X_{i}(k)$ and $Y(k)$ have been calculated, the average value of those correlation coefficients have to be calculated, which is termed as relational grade of $X_{\mathrm{i}}(k)$ and $Y(k)$.

\subsection{Evaluation Model}

The financing risk evaluation includes two parts. One is the evaluation of the present value of the financing risk factor. The other is the evaluation of the maximum value of the financing risk factor at the same time point. The realization of surveillance is based on the comparison between the present value and the maximum value.

The determination of the maximum value, here, will adopt the Delphi method.

The calculation of the present value will adopt interval estimation method, which not only has the ability of dealing with the judgment of uncertainty, but also can easily gather different opinions, thus reducing the random error of experts' judgments.

The detailed interval estimation method steps are shown as follows.

Set the ith expert and give the present estimation interval as: $\left(u_{1}^{(i)}, u_{2}^{(i)}\right)$ series as

If the number of expert is $n, n$ judgment intervals can be achieved to form a statistical set

$$
\left(u_{1}^{(1)}, u_{2}^{(1)}\right),\left(u_{1}^{(2)}, u_{2}^{(2)}\right), \ldots,\left(u_{1}^{(n)}, u_{2}^{(n)}\right)
$$

Those $n$ subsets are superposed together to form a distribution termed as sample falling shadows function covering over the evaluation axis. The function is marked as $\widehat{X}(u)$.

The estimated value of the financing risk factor can be calculated by the following equation.

$$
\hat{X_{(u)}}=\frac{1}{n} \sum_{k=1}^{n} X\left[u_{1}^{(n)}, u_{2}^{(n)}\right] u, X\left[u_{1}^{(n)}, u_{2}^{(n)}\right] u=\left\{\begin{array}{c}
o, \text { the other } \\
1, u_{1}^{(i)} \leqslant u \leqslant u_{2}^{(i)},
\end{array}, \frac{\int_{\min }^{\max } u \hat{X}(u) d u}{\int_{\min }^{\max } \hat{X}(u) d u}\right.
$$

Among this equation, $u_{\max }$ and $u_{\min }$ are respectively the maximum and the minimum value that $u$ can reach.

\section{Empirical Study}

The example is taken from Qingdao Jiaozhou Bay Subsea Tunnel project in China. The total length of the tunnel is around 7.8 kilometers, with a $3.95 \mathrm{~km}$ long section under the sea. The total investment reaches 3.3 billion yuan. Capitals is mainly provided from these 5 entities in China, Qingdao Guoxin Group, Qingdao Guoxin Jiaozhou Bay Transportation Co. LTD, China Development Bank, Qingdao Municipal Government and China Railway Tunnel Group. The individual stakeholder will take Qingdao Guoxin Group as an example. Now, the surveillance system is demonstrated here.

\subsection{Overall Evaluation Indicator System of Qingdao Jiaozhou Bay Subsea Tunnel Project in China}

Currently, the indicator system of financing risks in the large-scale project has no uniform standard. The questionnaire has been designed mainly based on the financing situation of Qingdao Jiaozhou Bay Subsea Tunnel project in China. The questionnaires have been allocated to relevant professors in the universities, government officials and experts in the construction project financing. The financing risk factors can be established in the main body construction phase of Qingdao Jiaozhou Bay Subsea Tunnel project in China. There are 17 kinds of financing risk factors in the Qingdao Jiaozhou Bay Subsea Tunnel project, which is shown in Table1 


\begin{tabular}{|c|c|}
\hline \multirow{6}{*}{ 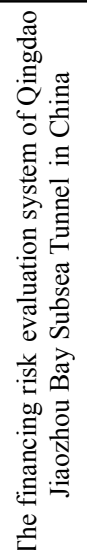 } & Risk indicators \\
\hline & $\begin{array}{l}\text { Political situation } X_{1} \text {, Political and economic law } X_{2} \text {, Exchange rate } X_{3} \text {, } \\
\text { Interest rate } X_{4} \text {, Inflation } X_{5}\end{array}$ \\
\hline & $\begin{array}{l}\text { Ill-consideration of geological conditions } \mathrm{X}_{6} \text {, Ill-consideration of } \\
\text { constructability } \mathrm{X}_{7}\end{array}$ \\
\hline & $\begin{array}{l}\text { Perfection degree of laws and regulations } \mathrm{X}_{8} \text {, Omission of contract terms } \mathrm{X}_{9} \text {, } \\
\text { Supervision of the enforcement of laws and regulations } \mathrm{X}_{10}\end{array}$ \\
\hline & $\begin{array}{l}\text { Construction technologies and solutions } X_{11} \text {, Pollution caused by the } \\
\text { transportation of waste and hazardous substances } X_{12} \text {, Applicability of } \\
\text { management technology } X_{13} \text {, Complexity of engineering geological } \\
\text { conditions } X_{14}\end{array}$ \\
\hline & Technical risk $\mathrm{X}_{15}$, Completion cost overrun $\mathrm{X}_{16}$, Price risk $\mathrm{X}_{17}$ \\
\hline
\end{tabular}

Table 1: Overall Evaluation Indicator System of Qingdao Jiaozhou Bay Subsea Tunnel in China

\subsection{FinancingRisk Sharing (Financing risk indicators of Qingdao Guoxin Group)}

The original data is transformed to THE target data by the processing of information technologies (Data Warehouse, Data Mining and Online Analytical Processing). With the help of the MATLAB, the target data are processed by sharing model (the method integrated with grey relational grade analysis and entropy method). Then, Qingdao Guoxin Group gets its own financing risk factors. As the limitation of the space of this paper, only 3 key tables will be presented here, which are shown in Table 2, Table 3 and Table 4.

From Table 4, it is known that financing risks X5, X8, and X9 are listed in front of all kinds of risk factors, which indicates the Qingdao Guoxin Group needs to take 3 kinds of financing risks caused by inflation, perfection of laws and regulations and omission of contract terms.

\subsection{Comparison between the Present Value and the Bearable Maximum Value of Every Financing Risk Factor of Qingdao Guoxin Group in China}

This paper here uses interval estimation method to further calculate the financing risks concerning inflation, perfection of laws and regulations and omission of contract terms one by one, which are taken by Qingdao Guoxin Group. Then compare the every outcome with the bearable maximum value obtained by Delphi method. The calculating result is shown in Table 5 .

Finally, through human machine interaction, Qingdao Guoxin Group, as an individual stakeholder, can clearly grasp the situation of the three kinds of financing risk factors.

\begin{tabular}{|l|l|l|l|l|l|l|l|l|l|}
\hline Indicators & $\mathrm{X}_{1}$ & $\mathrm{X}_{2}$ & $\mathrm{X}_{3}$ & $\mathrm{X}_{4}$ & $\mathrm{X}_{5}$ & $\mathrm{X}_{6}$ & $\mathrm{X}_{7}$ & $\mathrm{X}_{8}$ & $\mathrm{X}_{9}$ \\
\hline Entropy & 0.991 & 0.983 & 0.984 & 0.983 & 0.966 & 0.989 & 0.988 & 0.973 & 0.974 \\
\hline Entropy weight & 0.036 & 0.070 & 0.068 & 0.070 & 0.145 & 0.048 & 0.052 & 0.116 & 0.109 \\
\hline Indicators & $\mathrm{X}_{10}$ & $\mathrm{X}_{11}$ & $\mathrm{X}_{12}$ & $\mathrm{X}_{13}$ & $\mathrm{X}_{14}$ & $\mathrm{X}_{15}$ & $\mathrm{X}_{16}$ & $\mathrm{X}_{17}$ & \\
\hline Entropy & 0.993 & 0.993 & 0.983 & 0.993 & 0.993 & 0.979 & 0.986 & 0.988 & \\
\hline Entropy weight & 0.031 & 0.031 & 0.070 & 0.031 & 0.031 & 0.087 & 0.057 & 0.051 & \\
\hline
\end{tabular}

Table 2 : Financing Risk Indicators Entropy and Weight of Qingdao Guoxin Group in China 


\begin{tabular}{|l|l|l|l|l|l|l|l|l|l|l|l|l|l|l|l|l|l|}
\hline & $\mathrm{X}_{1}$ & $\mathrm{X}_{2}$ & $\mathrm{X}_{3}$ & $\mathrm{X}_{4}$ & $\mathrm{X}_{5}$ & $\mathrm{X}_{6}$ & $\mathrm{X}_{7}$ & $\mathrm{X}_{8}$ & $\mathrm{X}_{9}$ & $\mathrm{X}_{10}$ & $\mathrm{X}_{11}$ & $\mathrm{X}_{12}$ & $\mathrm{X}_{13}$ & $\mathrm{X}_{14}$ & $\mathrm{X}_{15}$ & $\mathrm{X}_{16}$ & $\mathrm{X}_{17}$ \\
\hline 1 & 0.42 & 0.52 & 0.61 & 0.42 & 0.67 & 0.52 & 0.42 & 0.52 & 0.67 & 0.42 & 0.52 & 0.52 & 0.52 & 0.52 & 0.67 & 0.52 & 0.42 \\
\hline 2 & 0.52 & 0.67 & 0.54 & 0.52 & 0.52 & 0.67 & 0.52 & 0.67 & 0.52 & 0.52 & 0.52 & 0.67 & 0.52 & 0.42 & 0.67 & 0.67 & 0.52 \\
\hline 3 & 0.52 & 0.42 & 0.42 & 0.52 & 0.67 & 0.52 & 0.67 & 0.77 & 0.52 & 0.42 & 0.52 & 0.67 & 0.42 & 0.52 & 0.52 & 0.52 & 0.42 \\
\hline 4 & 0.52 & 0.60 & 0.52 & 0.42 & 1.00 & 0.42 & 0.52 & 1.00 & 0.77 & 0.52 & 0.42 & 0.42 & 0.42 & 0.52 & 0.42 & 0.42 & 0.52 \\
\hline 5 & 0.42 & 0.52 & 0.48 & 0.41 & 0.52 & 0.42 & 0.42 & 0.67 & 1.00 & 0.34 & 0.42 & 0.52 & 0.42 & 0.42 & 0.42 & 0.42 & 0.52 \\
\hline 6 & 0.34 & 0.52 & 0.54 & 0.67 & 1.00 & 0.34 & 0.52 & 0.52 & 0.67 & 0.52 & 0.34 & 0.42 & 0.34 & 0.52 & 0.52 & 0.34 & 0.42 \\
\hline 7 & 0.42 & 0.34 & 0.41 & 0.67 & 0.68 & 0.42 & 0.34 & 0.52 & 0.67 & 0.42 & 0.42 & 0.34 & 0.42 & 0.34 & 0.34 & 0.42 & 0.34 \\
\hline 8 & 0.42 & 0.68 & 0.37 & 0.52 & 1.00 & 0.51 & 0.44 & 0.67 & 1.00 & 0.42 & 0.52 & 0.42 & 0.52 & 0.42 & 0.42 & 0.52 & 0.42 \\
\hline 9 & 0.60 & 0.52 & 0.64 & 0.42 & 0.52 & 0.42 & 0.52 & 0.52 & 0.67 & 0.52 & 0.52 & 0.42 & 0.52 & 0.52 & 0.52 & 0.34 & 0.67 \\
\hline 10 & 0.35 & 0.52 & 0.60 & 0.34 & 0.67 & 0.42 & 0.52 & 1.00 & 0.52 & 0.52 & 0.42 & 0.52 & 0.42 & 0.52 & 0.67 & 0.42 & 0.52 \\
\hline
\end{tabular}

Table 3 :Correlation Coefficient of Financing Risk Indicators of Qingdao Guoxin Group in China

\begin{tabular}{|l|l|l|l|l|l|l|l|l|l|}
\hline Indicator & $\mathrm{X}_{1}$ & $\mathrm{X}_{2}$ & $\mathrm{X}_{3}$ & $\mathrm{X}_{4}$ & $\mathrm{X}_{5}$ & $\mathrm{X}_{6}$ & $\mathrm{X}_{7}$ & $\mathrm{X}_{8}$ & $\mathrm{X}_{9}$ \\
\hline Relational grade & 0.15 & 0.33 & 0.35 & 0.33 & 1.05 & 0.22 & 0.25 & 0.78 & 0.75 \\
\hline Ranking & 11 & 6 & 5 & 6 & 1 & 10 & 8 & 2 & 3 \\
\hline Indicator & $\mathrm{X}_{10}$ & $\mathrm{X}_{11}$ & $\mathrm{X}_{12}$ & $\mathrm{X}_{13}$ & $\mathrm{X}_{14}$ & $\mathrm{X}_{15}$ & $\mathrm{X}_{16}$ & $\mathrm{X}_{17}$ & \\
\hline Relational grade & 0.15 & 0.15 & 0.33 & 0.15 & 0.15 & 0.55 & 0.25 & 0.23 & \\
\hline Ranking & 12 & 12 & 6 & 12 & 12 & 4 & 7 & 9 & \\
\hline
\end{tabular}

Table 4: Relational Grade of Financing risks of Qingdao Guoxin Group in China

\begin{tabular}{|l|l|l|l|l|}
\hline Stakeholder & Risk indicator & Present risk value & $\begin{array}{l}\text { Maximum risk } \\
\text { value }\end{array}$ & Display lamp \\
\hline \multirow{4}{*}{ Qingdao Guoxin Group } & Inflation $\mathrm{x} 5$ & 6.562 & 7.231 & Yellow \\
\cline { 2 - 5 } & Perfection of laws and regulations $\mathrm{x} 8$ & 4.031 & 8.346 & Green \\
\cline { 2 - 5 } & Omission of contract terms $\mathrm{x} 9$ & 6.343 & 7.514 & Yellow \\
\hline
\end{tabular}

Table 5 : Comparison between the Present Value and the Bearable Maximum Value of Financing Risks of Qingdao Guoxin Group in China

\section{Conclusion}

With the help of modern information technologies (Data Warehouse, Data Mining and Online Analytical Processing), this paper builds the surveillance system of financing risks in large-scale construction project from the perspective of individual stakeholder. It has four prominent features. The first is specification, taking the individual stakeholder as the research perspective. The second one is dynamic, taking time into account. The third feature is the analytical method combined with many mature modern theories and methods. The last one is easy to be understood and used by the individual stakeholder

The surveillance system in this paper can solve three problems effectively. Firstly, the target is specific. With the financing risk sharing model, the individual stakeholder can obtain his financing risk factors at the present stage. The second problem solved is accuracy. With the financing risk evaluating model, the individual stakeholder can achieve his financing risk state at the present stage. The third one has solved dynamics. With the help of the modern technologies, the constant monitoring can be realized.

Empirical study also shows the scientific rationality of the surveillance system. This surveillance system provides a valuable tool for individual stakeholder to grasp its own financing risks timely and accurately. 


\section{References}

[1] Robert R Van Der Velde, Disk Pieter Van Donk. Understanding project management: engineering complex industrial construction projects [J]. International Journal of Project Management. 20, 525533 (2002).

[2] Sudong Ye, Project Finance - Theory and Case [M]. Beijing. Tsinghua University Press. pp. 152164 (2008) (In Chinese)

[3] Jinlu Liu. Project Finance Risk-sharing, Control Model and Empirical Analysis - Based on TEDA Project Finance Related Research [D]. Tianjin. Tianjin University (2007) (In Chinese)

[4] Huaixiu Ren. Project Financing [M]. Beijing. Renmin University Press. pp. 85-121 (2013) (In Chinese)

[5] Guotai Chi, Wei Wang. Comprehensive Evaluation Theory, Method and Application Based on Scientific Development. [M]. Beijing. Science Press. pp. 167-192 (2009) (In Chinese)

[6] Zhao Hui, Wang Xueqing. A Method Based on PCA and BP Neural Network Improved by GA for Evaluating the Highway Financing Risk [J]. Journal of Science and Technology Management Research, 08, 209-202 (2010) (In Chinese)

[7] Wibowo, Andreas. Financial risk analysis of project finance in Indonesian toll roads [J].Journal of Construction Engineering and Management. 131(9), 963-972 (2005)

[8] Motawa, I.A., Anumba, C.J., EI-Hamalawi. A fuzzy system for evaluating the risk of change in construction projects [J]. Advances in Engineering Software. 37(9), 583-591 (2006)

[9] Dikmen, I., Birgonul, M.T., Han, S. Using fuzzy risk assessment rate cost overrun risk in international construction projects [J]. International Journal of Project Management. 25(5), 494-505 (2007)

[10] Ebrahinmeijad.S, Mousavi.S.M. A fuzzy BOT project risk evaluation model in Iranian power plant industry $[\mathrm{C}]$.International Conference on Industrial Engineering and Engineering Management. IEEM 2008. IEEE International Conference on, vol., no., pp.1038,1042, 8-11 Dec. (2008)

[11] Yongkang Shi, Chao Han. An analytical method for out-of-plane relative equilibrium formation using inter-spacecraft forces [J], Acta Astronautica. Volume 109, 124-131 (2015)

[12] Dequan \& Tiong Robert L.K. Assessment of credit risk in project finance [J].Journal of Construction Engineering and Management. 134(11), 876-884 (2012)

[13] Fabreqat, Marlo Aymerich. Construction risk in project financing [J]. Revista de Obras Publicas. $149,77-84(2002)$

[14] Xiaojun Fan, Fanghua Wang, Genhua Zhong. Dynamic fuzzy evaluation of large infrastructure project financing risk [J]. Journal of Shanghai Jiaotong University, 03, 450-452 (2004) (In Chinese)

[15] Wei Tang, Hailong Wu. PPP project financing efficiency research based on the government's point of view----Take BOT and BOO models as examples [J]. Science Research Management. 35(1),157-162 (2014) (In Chinese)

[16] Timothy Irwin. Risk Management Theory and Tool [J]. International Journal of Project Management. 15(2), 202-208 (2010)

[17] Shouqing Wang, Yongjian Ke. Concession Project Financing (BOT, PFI and PPP) [M]. Beijing. Tsinghua University Press. pp. 32-48 (2008) (In Chinese)

[18] Shuibo Zhang, Bosen He. Guidance and Analysis of the New FIDIC Conditions [M]. Beijing. China Building Industry Press. pp. 67-89 (2003). (In Chinese) 